\title{
Estudo comparativo entre as diferentes cores de ligaduras elásticas
}

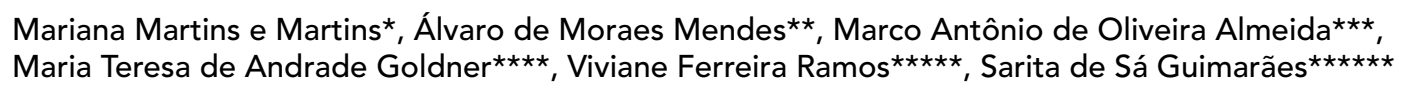

Resumo

Objetivo: avaliar as diversas cores de ligaduras elásticas do tipo modular da marca Morelli. Metodologia: estas ligaduras foram estiradas em cilindros de aço inoxidável com diâmetro aproximado de um braquete de incisivo central superior, imersas em saliva artificial a $37^{\circ} \mathrm{C}$ e tiveram suas forças medidas em uma máquina de ensaios de tração, antes da colocação nos estiletes (0h) e após 24 horas de imersão em saliva artificial. Os resultados foram obtidos através de um computador que opera conectado à máquina de tração e foram submetidos a testes estatísticos (ANOVA e Tuckey) com $\mathrm{p} \leq 0,05$. Resultados e Conclusões: as médias das forças obtidas foram: $m d=0,3792 \mathrm{KgF}$ para $0 \mathrm{~h}$ e $\mathrm{md}=0,1286 \mathrm{KgF}$ para $24 \mathrm{~h}$ e o desvio padrão do percentual de degradação da força foi de $66,07 \% \pm 2,31 \%$. Diante dos resultados, pode-se concluir que existe uma diferença significativa entre as forças geradas em $0 \mathrm{~h}$ e $24 \mathrm{~h}$. Em $0 \mathrm{~h}$, mesmo antes da ação do tempo e da imersão em saliva artificial, já existem diferenças significativas entre algumas cores, com valores mais altos $(\mathrm{md}=0,4024 \mathrm{KgF})$ para a pérola e mais baixos $(\mathrm{md}=0,3511 \mathrm{KgF})$ para a verde clara. Em $24 \mathrm{~h}$, também foram constatadas diferenças significativas, sendo que a distribuição das cores por grupos foi diferente da observada em $0 \mathrm{~h}$. As cores verde clara, vermelha, amarela e branca tiveram menor percentual de degradação da força, sendo a verde clara com melhor desempenho $(62,60 \%)$. Já as cores pérola, prata e cinza demonstraram maior percentual, sendo a pérola com pior desempenho $(69,23 \%)$.

Palavras-chave: Elastômeros. Ligadura. Cor. Elasticidade.

\section{INTRODUÇÃO}

As ligaduras elásticas são utilizadas para fixar os arcos ortodônticos aos braquetes. Estas apresentam algumas vantagens como propriedade de memória elástica, são de fácil colocação, são confortáveis para o paciente, possuem biocompatibilidade, são de fácil higienização e estão disponíveis em várias cores, contribuindo para a motivação do paciente com o tratamento ortodôntico. No entanto, também apresentam desvantagens como não serem capazes de liberar níveis de forças constantes por longo período de tempo e sofrerem alterações em suas propriedades físicas $3,4,6,8,9,17,18,19$.

Apesar de seu amplo emprego, existem poucos

\footnotetext{
* Especialista em Ortodontia pela UERJ. Professora de Ortodontia da UVA

** Mestre e Doutor em Ortodontia pela UFRJ. Professor adjunto de Ortodontia da UERJ e UVA.

$\star \star \star \star$ Livre docente pela UERJ. Mestre em Ortodontia pela UFRJ. Professor titular de Ortodontia da UERJ

**** Mestre em Odontologia pela UERJ. Professora assistente de Ortodontia da UERJ e UVA.

$\star \star \star \star \star$ Especialista em Ortodontia da UVA.
} 
trabalhos que avaliam as ligaduras elásticas em relação às suas propriedades físicas. A maioria dos trabalhos sobre elastômeros, disponíveis na literatura ortodôntica, está voltada para os elásticos em cadeia. Mesmo sendo as ligaduras elásticas confeccionadas com o mesmo material dos elásticos em cadeia, as aplicações clínicas são diferentes, portanto as respostas podem também ser diferentes ${ }^{18}$. Praticamente não existem trabalhos sobre ligaduras elásticas e os poucos trabalhos disponíveis demonstraram apenas valores estatisticamente significativos para o percentual de degradação da força no intervalo de 24 horas, após este período, a degradação não foi mais significativa ${ }^{1,16}$. Além do mais, ainda persistem dúvidas sobre a influência da pigmentação utilizada na manufatura das ligaduras elásticas coloridas em relação ao percentual de degradação da força. Portanto, o objetivo deste estudo foi avaliar o comportamento das ligaduras elásticas coloridas do tipo modular, em relação à intensidade das forças geradas e em relação ao percentual de degradação das forças no intervalo de $0 \mathrm{~h}$ a 24 horas.

\section{REVISÃO DE LITERATURA}

O termo elastômero se refere a materiais que retornam a sua configuração inicial após sofrerem consideráveis deformações ${ }^{3}$. Provavelmente, o primeiro material elástico conhecido foi a borracha natural utilizada por civilizações Maias e Incas. A matéria-prima destas borrachas naturais era obtida da árvore Hevea brasiliensis que pode ser encontrada na Amazônia. Porém, o uso destas borrachas era limitado devido às suas propriedades físicas de absorção de água e instabilidade térmica. Com o advento da vulcanização, preconizado por Charles Goodyear em 1839, as propriedades físicas das borrachas foram melhoradas, fazendo com que a utilização deste material aumentasse consideravelmente ${ }^{3,14}$. De acordo com Baty et al. ${ }^{3}$, os primeiros ortodontistas que defenderam a utilização de elásticos de borracha natural na prática ortodôntica foram Angle, Case e Baker.

A utilização de borrachas naturais para certas finalidades ainda era limitada, em grande parte, devido ao fato destas se deteriorarem consideravelmente na presença de oxigênio. Os cientistas então se concentraram em produzir uma borracha sintética semelhante e com propriedades físicas melhores que a borracha natural. No mesmo momento, o mercado exigia tal desenvolvimento devido à escassez da borracha natural em decorrência da primeira guerra mundial. Felizmente, agentes químicos foram desenvolvidos para inibir algumas reações indesejáveis como os antioxidantes e os anti-ozonizantes ${ }^{3,14}$. Os elásticos sintéticos são produzidos a partir de materiais poliuretanos derivados do petróleo, cuja composição exata é segredo do fabricante. A composição interna destes materiais é determinada pelo nível de tecnologia empregada e pela qualidade das matérias-primas empregadas na manufatura do material ${ }^{15}$. Os elastômeros poliuretanos mais utilizados em Ortodontia são os elásticos em cadeia e as ligaduras elásticas.

Quimicamente, os elastômeros são considerados polímeros. A origem grega da palavra explica sua estrutura, onde "poli" significa muitas e "meros", partes. São substâncias compostas por várias moléculas que se repetem formando uma cadeia à parte das unidades fundamentais, que são denominadas monômeros ${ }^{14}$. Estes polímeros são compostos por ligações primárias e secundárias com fraca atração molecular. Inicialmente, o polímero apresenta um padrão espiral e quando este se deforma, devido à aplicação de uma força, as cadeias poliméricas se ordenam em uma estrutura linear com ligações cruzadas em alguns pontos ao longo das mesmas. A modificação do padrão espiral para linear ocorre devido às fracas ligações secundárias, enquanto a recuperação de sua estrutura inicial se deve às custas das ligações cruzadas. A deformação permanente só ocorre quando o polímero é distendido acima de seu limite elástico, promovendo a quebra das ligações cruzadas. O elastômero ideal seria aquele que após ser distendido abaixo do seu limite elástico retornaria à sua exata configuração inicial. Porém, sabe-se que esta situação é utópica, pois algumas 
cadeias poliméricas distendidas deslizam de modo irreversivel umas sobre as outras e obtem-se um novo arranjo espacial ${ }^{13}$.

Os elastômeros sintéticos utilizados em Ortodontia quando são estendidos e expostos ao ambiente oral absorvem água e saliva e sofrem quebra de suas ligações internas, promovendo uma deformação permanente. Também apresentam rápida perda de força devido ao efeito de relaxação, resultando em perda gradual de sua efetividade. Vários estudos com elásticos em cadeia demonstraram que estes elásticos não conseguem produzir níveis constantes de força por um longo período de tempo e que a maior perda de força ocorre nas primeiras horas. Após este período, a perda se

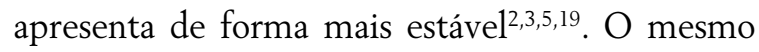
ocorreu com as ligaduras elásticas no estudo de Souza $^{16}$ e de Abrão ${ }^{1}$.

\section{MATERIAL E MÉTODO}

\section{Amostra e equipamento utilizado Amostra}

Neste estudo foram utilizadas ligaduras elásticas ortodônticas do tipo modular da marca Morelli (Fig. 1) das cores verde clara (REF. 60.06.114), azul clara (REF. 60.06.103), azul escura (REF. 60.06.115), vermelha (REF. 60.06.109), laranja (REF. 60.06.113), rosa (REF. 60.06.111), uva (REF. 60.06.112), marrom (REF. 60.06.108), preta (REF. 60.06.110), amarela (REF. 60.06.104), dourada (REF. 60.06.116), transparente (REF. 60.06.100), pérola (REF. 60.06.102), branca (REF. 60.06.105), prata (REF. 60.06.117) e cinza (REF. 60.06.101). As ligaduras apresentam a espessura de $0,75 \mathrm{~mm}$, com $1,5 \mathrm{~mm}$ de diâmetro interno e $3 \mathrm{~mm}$ de diâmetro externo. Todos os elásticos pertenciam ao mesmo lote, foram obtidos diretamente do fabricante e, até o início do experimento, foram mantidos em suas embalagens plásticas originais, guardados sob refrigeração e do abrigo da luz, eliminando assim, eventuais alterações causadas por variações na temperatura e luminosidade.

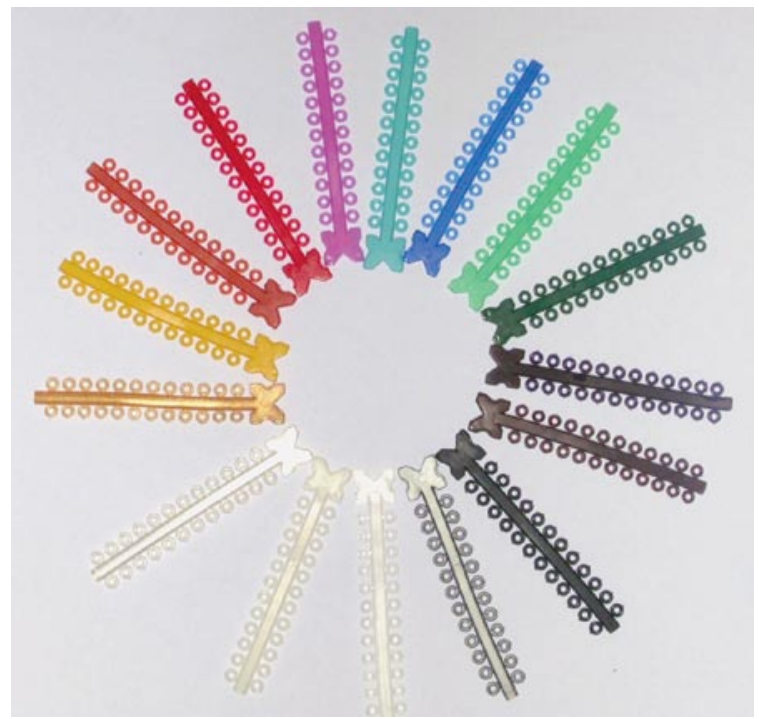

FIGURA 1 - Ligaduras coloridas do tipo modular da marca Morelli.

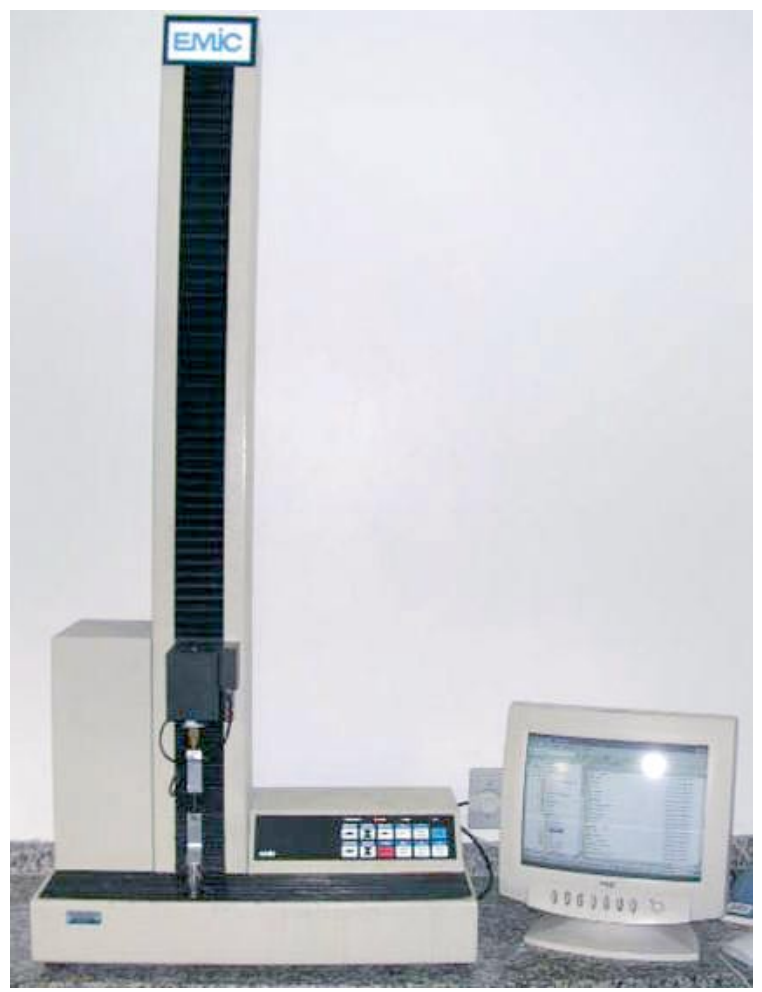

FIGURA 2 - Máquina de ensaio de tração DL-500 MF (EMIC).

\section{Equipamento utilizado}

A determinação da intensidade das forças liberadas pelas amostras foi realizada através do esti- 
ramento das mesmas em uma máquina de ensaios de tração, modelo DL-500 MF (EMIC - Equipamentos e Sistemas de Ensaios Ltda), do laboratório de ensaios físicos e mecânicos da Faculdade de Odontologia da UERJ, equipada com transdutores de medição de forças ou strain-gauges (EMIC Equipamentos e Sistemas de Ensaios Ltda), correspondente a uma carga de 1 Newton (equivalente a $9,80665 \mathrm{KgF}$ ) e ganchos de aço inoxidável com $1,29 \mathrm{~mm}$ de diâmetro para fixação das ligaduras elásticas (Fig. 2).

A máquina de ensaios de tração operou conectada a um computador (Intel Pentium 233 MMX), sendo este comandado pelo software Mtest (versão 1.01, EMIC- Equipamentos e Sistemas de Ensaios LTDA), permitindo a saída de dados através de uma impressora a jato de tinta (Hewlett-Packard 695). Todo o equipamento foi calibrado por técnicos qualificados da EMIC, de acordo com as características e parâmetros adotados na presente pesquisa.

\section{Preparo da amostra}

A amostra foi constituída de 320 ligaduras elásticas, sendo 10 ligaduras de cada cor para os tempos Oh e $24 \mathrm{~h}$.

\section{Fixação das ligaduras elásticas nos estiletes de aço inoxidável}

Os corpos de prova dos 16 grupos de ligaduras coloridas foram armazenados em solução de saliva artificial, sendo as ligaduras elásticas transferidas para estiletes de aço inoxidável (cavalo de aço) através de um colocador de ligaduras para braquetes standard (Shooter - referência 100-357, TP Orthodontics), para padronizar o estiramento das mesmas e evitar possíveis deformações na estrutura das amostras durante sua colocação (Fig. 3). Estes estiletes de aço inoxidável são afilados em suas extremidades e possuem $10 \mathrm{~cm}$ de comprimento e $4 \mathrm{~mm}$ de diâmetro, que corresponde ao diâmetro aproximado que as ligaduras elásticas apresentam quando fixadas a um braquete de incisivo central superior da marca Morelli (REF. 1030

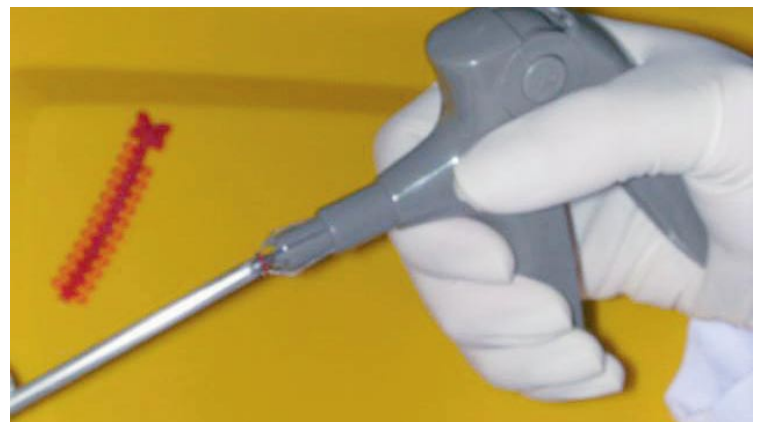

FIGURA 3 - Colocação da ligadura elástica colorida no estilete de aço inoxidável com o auxílio de um colocador de ligaduras para braquetes standard(Shooter - referência 100-357, TP Orthodontics).

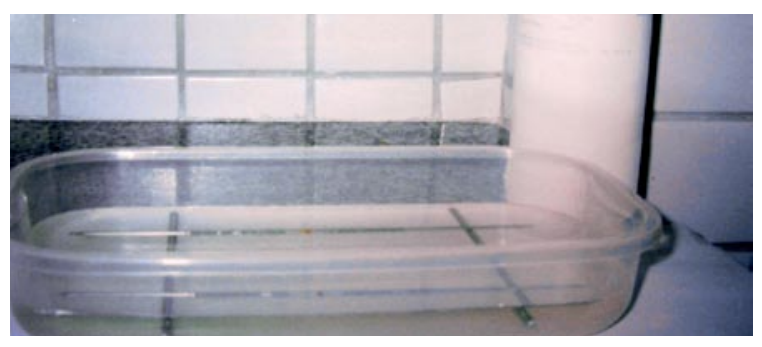

FIGURA 4 - Ligaduras elásticas coloridas adaptadas aos estiletes metálicos e imersas em solução de saliva artificial com pH=7 (Farmácia Universitária - UFRJ).

201) com um fio ortodôntico de aço inoxidável de 0,020" de diâmetro, posicionado em seu slot. Em seguida, as ligaduras permaneceram imersas em solução de saliva artificial (Farmácia Universitária UFRJ) com $\mathrm{pH}$ neutro ( $\mathrm{pH}=7$ ) e armazenadas em estufa bacteriológica (marca Fanen) à temperatura de $37^{\circ} \mathrm{C}$ por um período de 24 horas (Fig. 4).

A intensidade das forças liberadas pelas ligaduras elásticas foi medida no tempo 0 hora (grupos controle) e após o período de 24 horas de imersão em solução de saliva artificial.

Todos os materiais utilizados nos procedimentos experimentais desta pesquisa foram manuseados pelo operador utilizando luvas descartáveis de látex para procedimento (Satari).

\section{Avaliação das forças geradas}

Para a determinação da intensidade das forças liberadas, todas as ligaduras foram distendidas quatro vezes o valor do seu comprimento original, através da máquina de ensaios de tração, a qual foi ajustada 
para uma distância inicial de $1 \mathrm{~mm}$ e final de $4 \mathrm{~mm}$, com o auxílio de um paquímetro digital (referência 727-6/150, Starrett), onde foram determinados os limites mínimo e máximo entre os ganchos da máquina de testes, coincidentes com as distâncias inicial e final às quais as amostras deviam ser tracionadas (Fig. 5). A velocidade de distensão adotada foi de $5,08 \mathrm{~mm} /$ minuto $(0,2$ polegadas/minuto), conforme descrito por Kovatch et al. ${ }^{10}$

Os dados obtidos foram impressos através do software de gerenciamento Mtest no formato de relatórios, referentes à intensidade das forças geradas pelas amostras dos grupos controle e experimentais. Em seguida, os dados foram agrupados em tabelas, para se proceder à análise estatística.

O cálculo do percentual de degradação foi feito a partir dos valores médios das forças liberadas para cada um dos grupos analisados e correspondendo ao intervalo de tempo de permanência em saliva artificial (Oh e $24 \mathrm{~h}$ ).

\section{Tratamento estatístico}

Os resultados foram submetidos a testes estatísticos (ANOVA e Tuckey) e foi adotado o intervalo de confiabilidade de $5 \%(\mathrm{p} \leq 0,05)$. Inicialmente aplicou-se o teste ANOVA para constatar se existiam diferenças significativas nos valores das forças geradas para cada cor de ligadura nos dois tempos estudados ( $0 \mathrm{~h}$ e 24h). Posteriormente, buscou-se observar se existiam ou não diferenças significativas nos valores das forças geradas entre as diversas cores em cada tempo estudado (Oh e 24h). As cores foram agrupadas de modo que cada grupo não apresentasse diferença estatisticamente significativa entre seus componentes quando aplicado o teste ANOVA, porém, apresentasse diferença significativa entre cada grupo quando aplicado o teste de Tuckey. Desta forma foi possível identificar grupos de cores com comportamentos semelhantes em cada tempo estudado.

\section{RESULTADOS E DISCUSSÃO}

Foram calculadas as médias das forças geradas pelos 10 corpos de prova de cada cor nos tempos Oh e $24 \mathrm{~h}$. Em seguida, foram calculadas as médias gerais das forças nos tempos $0 \mathrm{~h}(\mathrm{md}=0,3792 \mathrm{KgF}$ ) e $24 \mathrm{~h}(\mathrm{md}=0,1286 \mathrm{KgF}$ ) e o desvio padrão do percentual de degradação da força $(66,07 \% \pm 2,31 \%)$ conforme informa a tabela 1 .

No primeiro tempo (0h), mesmo antes da ação do tempo e da imersão em solução de saliva artificial, já existiam diferenças significati-
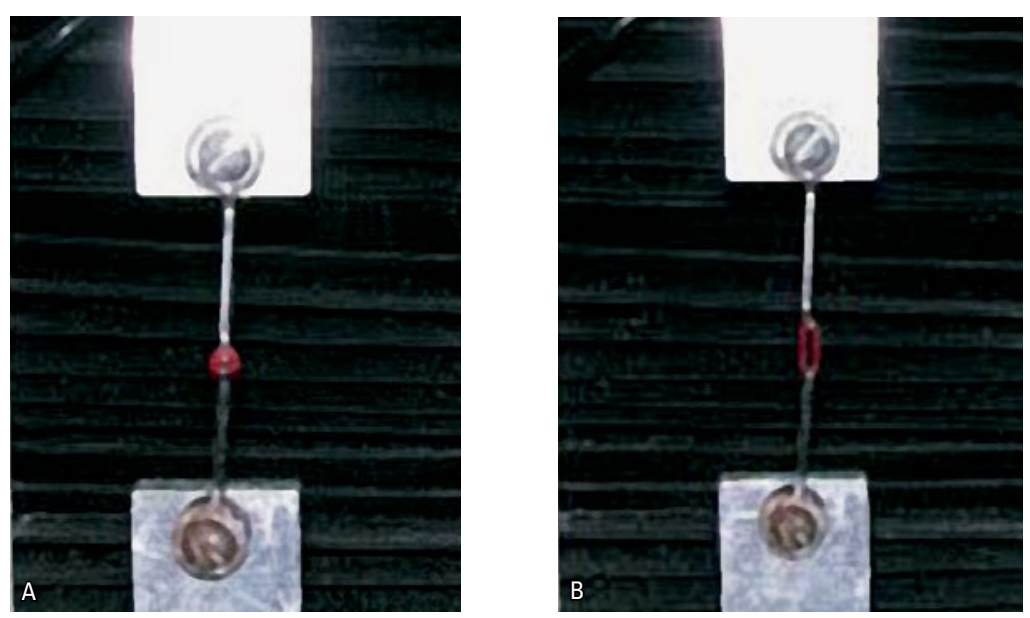

FIGURA 5 - Determinação dos limites A) mínimo e B) máximo entre os ganchos da máquina de testes, coincidentes com as distâncias inicial e final de distensão das ligaduras elásticas coloridas. 
Estudo comparativo entre as diferentes cores de ligaduras elásticas

Tabela 1 - Médias, percentuais de degradação e desvio padrão das forças geradas (KgF) nos tempos 0h e 24h.

\begin{tabular}{ccccccc}
\hline \multirow{2}{*}{ cores } & média das forças geradas em 0h & \multicolumn{2}{c}{ média das forças geradas em 24h } & \multicolumn{2}{c}{ degradação da força (\%) } \\
& $\mathbf{K g F}$ & devio padrão & KgF & devio padrão & \% & devio padrão \\
\hline verde claro & 0,3511 & $\pm 0,01889$ & 0,1313 & $\pm 0,005166$ & 62,60 & $\pm 3,90$ \\
azul claro & 0,3866 & $\pm 0,005456$ & 0,1377 & $\pm 0,001269$ & 64,38 & $\pm 0,21$ \\
azul escuro & 0,3713 & $\pm 0,007320$ & 0,1258 & $\pm 0,009405$ & 66,12 & $\pm 5,30$ \\
vermelho & 0,3822 & $\pm 0,008452$ & 0,1395 & $\pm 0,007642$ & 63,50 & $\pm 5,17$ \\
laranja & 0,3847 & $\pm 0,005503$ & 0,1337 & $\pm 0,01026$ & 65,25 & $\pm 5,51$ \\
rosa & 0,3692 & $\pm 0,008023$ & 0,1206 & $\pm 0,002428$ & 67,33 & $\pm 0,43$ \\
uva & 0,3706 & $\pm 0,01571$ & 0,1178 & $\pm 0,003534$ & 68,21 & $\pm 2,30$ \\
marrom & 0,3797 & $\pm 0,008522$ & 0,1271 & $\pm 0,008766$ & 66,53 & $\pm 3,18$ \\
preto & 0,3886 & $\pm 0,006406$ & 0,1237 & $\pm 0,003172$ & 68,17 & $\pm 1,79$ \\
amarelo & 0,3799 & $\pm 0,008835$ & 0,1418 & $\pm 0,003450$ & 62,67 & $\pm 2,03$ \\
dourado & 0,3904 & $\pm 0,008541$ & 0,1367 & $\pm 0,002632$ & 64,98 & $\pm 1,60$ \\
transparente & 0,3727 & $\pm 0,005377$ & 0,1190 & $\pm 0,003733$ & 68,07 & $\pm 1,49$ \\
pérola & 0,4024 & $\pm 0,006881$ & 0,1238 & $\pm 0,001845$ & 69,23 & $\pm 1,57$ \\
branco & 0,3812 & $\pm 0,005266$ & 0,1425 & $\pm 0,003077$ & 62,62 & $\pm 1,71$ \\
prata & 0,3826 & $\pm 0,004961$ & 0,1193 & $\pm 0,002492$ & 68,82 & $\pm 0,32$ \\
cinza & 0,3746 & $\pm 0,003738$ & 0,1174 & $\pm 0,003492$ & 68,66 & $\pm 1,13$ \\
média & $\mathbf{0 , 3 7 9 2}$ & $\pm \mathbf{0 , 0 1 1 0 4 5}$ & $\mathbf{0 , 1 2 8 6}$ & $\pm \mathbf{0 , 0 0 8 6 9 6}$ & $\mathbf{6 6 , 0 7}$ & $\pm \mathbf{2 , 3 1}$ \\
\hline
\end{tabular}

vas $(\mathrm{p}<0,05)$ entre algumas cores, com valores mais altos $(\mathrm{md}=0,4024 \mathrm{KgF})$ para a cor pérola e mais baixos $(\mathrm{md}=0,3511 \mathrm{KgF})$ para a verde clara (Tab. 1, Gráf. 1), sendo que a chance das ligaduras liberarem forças médias iguais em $0 \mathrm{~h}$ foi de $0,001 \%$. Estes dados indicam que o grupo 0 h não é homogêneo e sugere que o processo de manufatura que produz as diferentes cores pode ter influência na quantidade de força gerada. Alguns trabalhos, como a tese de Williams e Von Fraunhofer citada por Baty et al. ${ }^{3}$, já sugeriram que o material utilizado para colorir os elásticos em cadeia poderia promover alteração na quantidade de força inicial gerada e na capacidade do elástico em reter a força original. Porém, outros trabalhos não encontraram indícios que a coloração dos elásticos pudesse interferir de forma significativa na força inicial gerada ${ }^{1,16}$. Outro aspecto que merece atenção é o fato da força conferida ao produto ser determinada pela composição interna dos materiais. Portanto, a qualidade final do produto é dependente da qualidade da matériaprima utilizada, do grau de tecnologia empre- gado e do controle de qualidade exercido pelo fabricante. Como o presente estudo foi realizado apenas com um único lote de uma única marca com intuito de minimizar estas variáveis, apenas o controle do padrão de qualidade pode, de alguma forma, interferir nos resultados encontrados. Wong ${ }^{19}$ relatou que, em um mesmo lote, podem ser encontradas diferenças nas propriedades das ligaduras elásticas e que a quantidade de material presente em cada ligadura também pode ser diferente.

As demais cores foram agrupadas de modo que cada grupo não apresentasse diferenças estatisticamente significativas entre seus componentes quando aplicado o teste ANOVA $(\mathrm{p}<0,05)$, porém, apresentasse diferença significativa entre cada grupo e entre as cores pérola e verde clara quando aplicado o teste de Tuckey $(\mathrm{p}<0,05)$. Desta forma, foi possivel identificar grupos de cores com comportamento semelhante. Seguido da cor pérola (força média $=0,4024 \mathrm{KgF}$ ), o grupo formado pelas cores dourada, preta, azul clara e laranja liberou forças médias entre $0,3904 \mathrm{KgF}$ e $0,3847 \mathrm{KgF}$. 
Tabela 2 - Grupos de cores com comportamento semelhante nos tempos 0 h e $24 \mathrm{~h}$ quando aplicado o teste de Tuckey $(p<0,05)$.

\begin{tabular}{|c|c|c|c|}
\hline tempo & grupo & cores & média das forças geradas \\
\hline \multirow{5}{*}{ Oh } & 1 & pérola & $\mathrm{md}=0,4024 \mathrm{KgF}$ \\
\hline & 2 & $\begin{array}{l}\text { dourada, preta, } \\
\text { azul clara e } \\
\text { laranja }\end{array}$ & md entre $0,3904 \mathrm{KgF}$ e $0,3847 \mathrm{KgF}$ \\
\hline & 3 & $\begin{array}{c}\text { prata, vermelha, } \\
\text { branca, amarela } \\
\text { e marrom }\end{array}$ & md entre $0,3826 \mathrm{KgF}$ e $0,3797 \mathrm{KgF}$ \\
\hline & 4 & $\begin{array}{l}\text { cinza, trans- } \\
\text { parente, azul } \\
\text { escura, uva e } \\
\text { rosa }\end{array}$ & md entre $0,3746 \mathrm{KgF}$ e $0,3692 \mathrm{KgF}$ \\
\hline & 5 & verde clara & $\mathrm{md}=0,3511 \mathrm{KgF}$ \\
\hline \multirow{4}{*}{ 24h } & 1 & $\begin{array}{l}\text { branca, ama- } \\
\text { rela, vermelha e } \\
\text { azul clara }\end{array}$ & md entre $0,1425 \mathrm{KgF}$ e $0,1377 \mathrm{KgF}$ \\
\hline & 2 & $\begin{array}{c}\text { dourada, laranja } \\
\text { e verde clara }\end{array}$ & md entre $0,1367 \mathrm{KgF}$ e $0,1313 \mathrm{KgF}$ \\
\hline & 3 & $\begin{array}{c}\text { marrom, azul } \\
\text { escura, pérola e } \\
\text { preta }\end{array}$ & md entre $0,1271 \mathrm{KgF}$ e $0,1237 \mathrm{KgF}$ \\
\hline & 4 & $\begin{array}{l}\text { rosa, prata, } \\
\text { transparente, } \\
\text { uva e cinza }\end{array}$ & md entre $0,1206 \mathrm{KgF}$ e $0,1174 \mathrm{KgF}$ \\
\hline
\end{tabular}

Logo após, ficou o grupo formado pelas cores prata, vermelha, branca, amarela e marrom, com forças médias variando de $0,3826 \mathrm{KgF}$ a $0,3797 \mathrm{KgF}$. Em seguida, o grupo formado pelas cores cinza, transparente, azul escura, uva e rosa liberou forças médias entre $0,3746 \mathrm{KgF}$ e $0,3692 \mathrm{KgF}$. E, finalmente, o grupo verde claro que liberou força média equivalente a $0,3511 \mathrm{KgF}$ (Tab. 2).

No segundo tempo (24h), nenhuma cor mostrou diferença significativa de forma isolada (Tab. 1, Gráf. 2), porém a chance delas liberarem forças médias iguais foi praticamente nula $(0,000000000002 \%)$. Desta forma, as cores foram agrupadas obedecendo ao mesmo critério inicial, de forma que cada grupo não apresentasse diferença estatisticamente significativa entre seus componentes quando aplicado o teste ANOVA $(\mathrm{p}<0,05)$, porém apresentasse diferença significativa entre cada grupo quando aplicado o teste de Tuckey $(\mathrm{p}<0,05)$. As cores branca, amarela, ver- melha e azul clara não apresentaram diferenças significativas entre si e liberaram forças médias entre $0,1425 \mathrm{KgF}$ e $0,1377 \mathrm{KgF}$. O mesmo ocorreu com as cores dourada, laranja e verde clara com forças médias variando entre $0,1367 \mathrm{KgF}$ e $0,1313 \mathrm{KgF}$; entre as cores marrom, azul escura, pérola e preta com forças médias variando entre $0,1271 \mathrm{KgF}$ e $0,1237 \mathrm{KgF}$; e entre as cores rosa, prata, transparente, uva e cinza com forças médias variando entre $0,1206 \mathrm{KgF}$ e 0,1174KgF (Tab. 2). Como houve uma padronização no experimento, onde as diversas cores permaneceram pelo mesmo tempo imersas em solução de saliva artificial e foram distendidas com velocidade e distância padronizadas $(5,08 \mathrm{~mm} / \mathrm{min}$. e de $1 \mathrm{~mm}$ para $4 \mathrm{~mm}$ ), os resultados sugerem que os pigmentos utilizados para colorir as ligaduras elásticas podem ter influência na força gerada. Porém, esta afirmação só pode ser feita se existir um rígido controle de padrão de qualidade por parte do fabricante, conforme considerado por Taloumis et al. ${ }^{18} \mathrm{e}$ Wong ${ }^{19}$.

Foi constatado que houve diferenças estatisticamente significativas entre as forças médias geradas pelas ligaduras elásticas nos tempos $0 \mathrm{~h}$ e $24 \mathrm{~h}$ quando aplicado o teste ANOVA $(\mathrm{p}<0,05)$. $O$ cálculo do percentual médio de degradação das forças geradas pelas ligaduras coloridas foi de $66,07 \% \pm 2,31 \%$ (Tab. 1) comprovando, juntamente com outros estudos, que os elastômeros sintéticos utilizados em Odontologia são incapazes de gerar forças constantes durante um período considerável de tempo ${ }^{3}$. Os valores encontrados em relação ao percentual de degradação das forças geradas no presente estudo, confirmam os encontrados pela maioria dos autores que relatam uma variação entre $50 \%$ a $75 \%$ de perda da força inicial $^{2,3,5,7}$. As cores azul clara, azul escura, laranja, rosa, uva, marrom, preta, dourada e transparente apresentaram valores para o percentual de degradação da força dentro da média com desvio padrão, enquanto as cores verde clara, vermelha, amarela e branca apresentaram resultados melhores com valores menores que a média com desvio padrão, e as cores pérola, prata e cinza resultados piores, 
com percentuais de degradação das forças acima da média com desvio padrão (Tab.1, Gráf. 3).

A cor pérola que liberou forças médias significativamente maiores que as demais cores no tempo de 0 h não foi capaz de manter esta diferença no tempo $24 \mathrm{~h}$ e, quando foi calculado o percentual de degradação da força gerada, esta apresentou valores acima da média com desvio padrão. A cor verde clara que liberou forças médias significativamente menores que as outras cores no tempo de Oh, apresentou resultados melhores, já que o valor para o percentual de degradação da força gerada foi abaixo da média. Logo, pode-se dizer, com base neste estudo, que a força inicial gerada pelas ligaduras elásticas não é diretamente proporcional à sua efetividade em manter níveis de forças constantes, como constatado com os elásticos em cadeia no estudo de DeGenova et al. ${ }^{5}$, onde os elásticos que geraram forças iniciais maiores conseguiram reter maior quantidade de força ao longo do tempo.

As cores que apresentaram piores resultados com degradação da força acima da média foram as cores pérola $(69,23 \%)$, prata $(68,82 \%)$ e cinza $(68,66 \%)$. A forma inicial dos elastômeros se apresenta na cor cinza, as demais cores, inclusive a cristal, são obtidas a partir de pigmentos e materiais que tornam estes elastômeros transparentes. Estes procedimentos podem influenciar as forças geradas por estes materiais, tornando-os mais aptos a gerarem forças iniciais maiores e a reterem maior quantidade de força ao longo do tempo, justificando o melhor desempenho das demais cores em relação à cinza ${ }^{3,11,12}$. Porém, se os pigmentos utilizados forem metalizados, como nos casos das cores pérola, prata e dourada, estes promoverão redução na força e na elasticidade, levando ao prejuízo nas qualidades mecânicas do material ${ }^{8,13,19}$. Os resultados encontrados no presente estudo confirmam os dados encontrados na literatura, apenas a cor dourada que também possui pigmento metalizado não mostrou prejuízo em seu desempenho, conferindo um percentual de degradação da força gerada dentro da média $(64,98 \%)$.

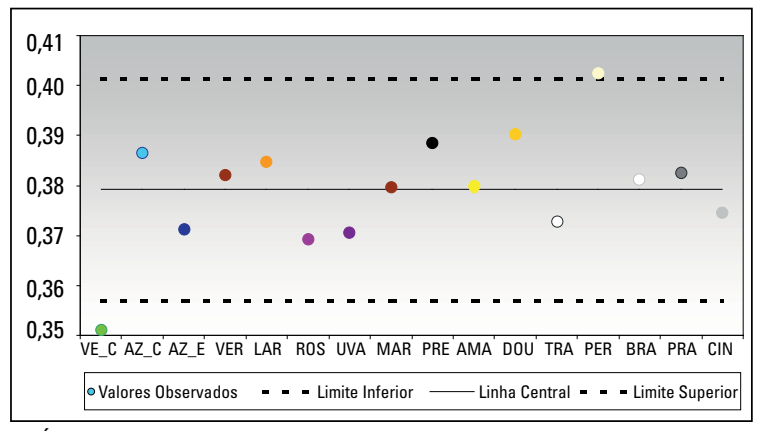

GRÁFICO 1 - Valores médios das forças geradas pelos elásticos de diferentes cores no tempo 0 hora.

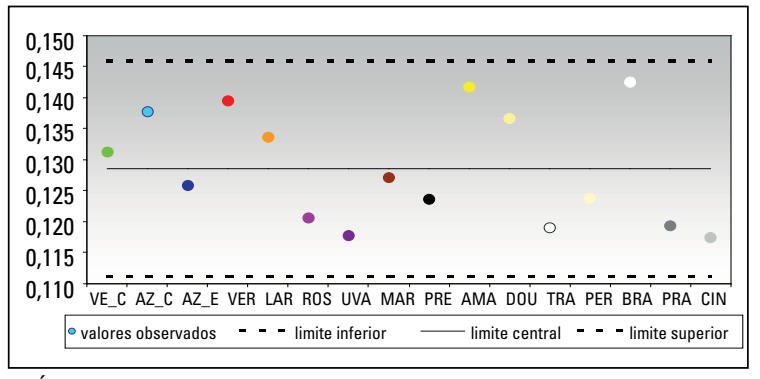

GRÁFICO 2 - Valores médios das forças geradas pelos elásticos de diferentes cores no tempo 24 horas.

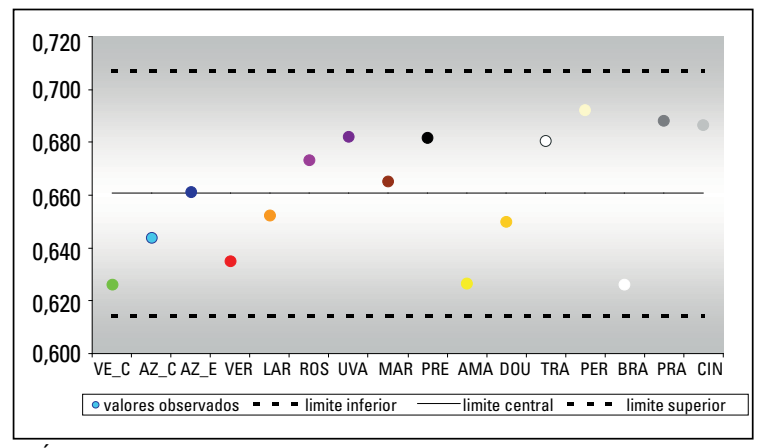

GRÁFICO 3 - Valores médios dos percentuais de degradação das forças geradas pelos elásticos de diferentes cores no período de 24 horas.

\section{CONCLUSÕES}

Em relação à força gerada, foi constatado que:

- Foi observada diferença significativa entre os valores médios das forças geradas no intervalo de 24 horas para todas as cores de ligaduras elásticas

- No tempo 0h, antes da distensão e imersão em saliva artificial, foram constatadas diferenças significativas entre os grupos de ligaduras elásti- 
cas, sendo que as cores pérola e verde clara apresentaram as maiores variações, correspondendo a $0,4024 \mathrm{KgF}$ e $0,3511 \mathrm{KgF}$, respectivamente.

- Após 24 horas de distensão e imersão em solução de saliva artificial, também foram constatadas diferenças significativas nos valores das forças geradas, sendo que a distribuição das cores por grupos de ligaduras foi diferente da observada em 0 h.

\section{Em relação ao percentual de degradação, foi} constatado que:

- As cores azul clara, azul escura, laranja, rosa, uva marrom, preta, dourada e transparente apresentaram desempenho dentro da média do grupo analisado $(66,07 \% \pm 2,31 \%)$.

- As cores verde clara, vermelha, amarela e branca apresentaram percentuais de degradação das forças geradas abaixo do valor médio do grupo analisado. Sendo que a cor verde clara apresentou o melhor desempenho $(62,60 \%)$.

- As cores pérola, prata e cinza apresentaram percentuais de degradação das forças geradas acima do valor médio do grupo analisado. Sendo que a cor pérola apresentou o pior desempenho $(69,23 \%)$.

\title{
Comparative study of different colors of molded elastomeric ligatures
}

\begin{abstract}
Aim: the purpose of this study was to evaluate the different colors of molded elastomerics ligatures from Morelli trademark. Methods: the ligatures were stretched over stainless dowels with a circumference approximating that of upper central incisor bracket. They were immersed in a synthetic saliva bath at $37^{\circ} \mathrm{C}$ and had force levels measured at initial (Oh) and after 24 hours of immersion. The results were obtained from a computer connected to a traction machine and were submitted to statistical analysis (ANOVA e Tuckey) with $p<0.05$. Results and Conclusion: the medium values were $\mathrm{md}=0.3792 \mathrm{KgF}$ for $\mathrm{Oh}$ and $\mathrm{md}=0.1286 \mathrm{KgF}$ for $24 \mathrm{~h}$ and the percentage of force decay were $66.07 \% \pm 2.31 \%$. The results revealed statically differences between forces delivered in $0 \mathrm{~h}$ and $24 \mathrm{~h}$. At $0 \mathrm{~h}$, there were differences statistically significance between some colors of ligatures before the action of the time and the immersion in artificial saliva bath, with higher values for the pearl $(\mathrm{md}=0.4024 \mathrm{KgF})$ and minors values for the slight green $(\mathrm{md}=0.3511 \mathrm{KgF})$. At $24 \mathrm{~h}$, it was also find differences statistically significances between some colors, but the distribution was different than the observed at Oh. The slight green, red, yellow and white colors had the minor percentage of force decay, in which slight green showed the best behavior (62.60\%). However, the pearl, silver and gray had the highest percentage of force decay, with pearl showing the worst behavior (69.23\%).
\end{abstract}

Key words: Elastomers. Ligature. Color. Elasticity.

\section{REFERÊNCIAS}

1. $A B R A ̃ O, L$. Avaliação da intensidade das forças liberadas por ligaduras elásticas de diferentes cores. 2004. Trabalho de Conclusão de Curso (Especialização em Ortodontia)-Faculdade de Odontologia, UERJ, Rio de Janeiro, 2004.

2. ANDREASEN, G. F.; BISHARA, S. E. Comparison of alastik chains with elastics involved with intra-arch molar to molar forces. Angle Orthod, Appleton, v. 40, no. 3, p.151-158, July 1970.

3. BATY, D. L.; STORIE, D. J.; VON FRAUNHOFER, J. A. Synthetic elastomeric chains: a literature review. Am J Orthod Dentofacial Orthop, St. Louis, v. 105, no. 6, p. 536-542, June 1994.

4. BISHARA, S. E.; ANDREASEN, G. F. A comparison of time related forces between plastic alastiks and latex elastics. Angle Orthod, Appleton, v. 4, no. 4, p. 319-328, Oct. 1970.
5. DeGENOVA, D. C.; McINNES-LEDOUX, P.; WEINBERG, R.; SHAYE, R. Force degradation of orthodontic elastomeric chains: a product comparison study. Am J Orthod Dentofacial Orthop, St. Louis, v. 87, no. 5, p. 377-384, May 1985.

6. HENRIQUES, J. F. C.; HAYASAKI, S. M.; HENRIQUES, R. P. Elásticos ortodônticos: como selecioná-los e utilizá-los de maneira eficaz. J Bras Ortodon Ortop Facial, Curitiba, v. 8, no. 48, p. 471-475, 2003.

7. HERSHEY, G.; REYNOLDS, W. The plastic module as an orthodontic tooth moving mechanism. Am J Orthod, St. Louis, v. 67, no. 5, p. 554-662, May 1975.

8. HUGET, E. F.; PATRICK, K. S.; NUNEZ, L. J. Observations on the elastic behavior of a synthetic orthodontic elastomer. J Dent Res, Baltimore, v. 69, no. 2, p. 496-501, Nov. 1990. 
9. JEFFRIES, C. L.: VON FRAUNHOFER, J. A. The effects of $2 \%$ alkaline glutaraldehyde solution on the elastic properties of elastomerics chain. Angle Orthod, Appleton, no. 1, p. 25-30, Jan./Mar. 1991.

10. KOVATCH, J. S.; LAUTENSCHLAGER, E. P.; APFEL, D. A.; KELLER, J.C. Load-extension-time behavior of orthodontic alastiks. J Dent Res, Chicago, v. 55, no. 5, p. 783-786, Sept./Oct. 1976.

11. LU, C. T.; WANG, W. N.; TARNG, T. H.; CHEN, J. W. force decay of elastomeric chain: a serial study. Am J Orthod Dentofacial Orthop, St. Louis, v. 104, no. 4, p. 373-377, Oct. 1993.

12. MATTA, E.N.R. Avaliação laboratorial da deformação plástica e da capacidade de liberação de força por elásticos plásticos. 1996. 86 f. Dissertação (Mestrado em Odontologia)-Faculdade de Odontologia, Universidade Federal do Rio de Janeiro, Rio de Janeiro, 1996.

13. MATTA, E. N. R.; CHEVITARESE, O. Avaliação laboratorial da força liberada por elásticos plásticos. Rev SBO. Rio de Janeiro, v. 4, n. 4, p. 131-136, Ago. 1997.
14. MILES, D. C.; BRISTON, J. H. Polymer technology. London: Temple Press, 1965.

15. MORTON, M. Rubber technology. 3rd ed. Londres: Chapman \& Hall, 1995

16. SOUZA, E.V. Avaliação das forças liberadas por ligaduras elásticas. 2003. Trabalho de Conclusão de Curso (Especialização em Ortodontia)-Faculdade de Odontologia, UERJ, Rio de Janeiro, 2003.

17. STEVENSON, S. J.; KUSY, P. R. Force application and decay characteristics of untreated and treated polyurethane elastomeric chains. Angle Orthod, Appleton, v. 64, no. 6, p. 455-467, Apr 1994.

18. TALOUMIS, J. L.; SMITH, T. M.; HONDRUM, S. O.; LORTON, L. Force decay and deformation of orthodontic elastomeric ligatures. Am J Orthod Dentofacial Orthop, St. Louis, v. 11, no. 1 p. 1-11, Jan. 1997.

19. WONG, A. K. Orthodontic elastics materials. Angle Orthod, Appleton, v. 46, no. 2, p. 196-204, Apr. 1976
Endereço para correspondência

Mariana Martins e Martins

Rua Voluntários da Pátria 190/609 - Botafogo

CEP: 22270-010 - Rio de Janeiro / RJ

E-mail: marianamartins@wnetrj.com.br 